\title{
WinDam: A Novel Airborne Wind Turbine
}

\author{
Ken Nagasaka, Amin Amini, and Mohammad Mehdi Vaez Momeni
}

\begin{abstract}
This paper presents the design, modeling and development of a novel airborne wind turbine composed of a tethered air dam supporting an embedded wind power generator, denoted as WinDam, which extracts energy from wind blowing between 50 and $300 \mathrm{~m}$ above the ground. The power generation and lift systems are integrated in this design; they do rely on each other for operation and design. The lift system is an air flyer with longitudinal control, lateral control and attack angle control capabilities. The tether serves to both anchor the device and to transmit electricity to the ground. The good matching between experimental data, collected by using an embedded system installed on the small-scale WinDam prototype, compared to computational fluid dynamic (CFD) analysis results reveal that WinDam can increase the flow stream wind velocity up to $193 \%$ at the location of generator due to low-pressure region behind the kite. Finally, WinDam has the potential to overcome the limits of the actual wind turbines and to provide large quantities of renewable energy.
\end{abstract}

Index Terms-Airborne wind energy, high-altitude wind energy, WinDam, wind energy.

\section{INTRODUCTION}

The cost of energy obtained from fossil sources is continuously increasing due to, increasing demand, related to the rapidly growing economies of the highly populated countries. Moreover, the detrimental effects of energy generation from fossil fuels on global warming and climate change, due to excessive carbon dioxide emissions, and the negative impact of fossil energy on the environment are big concerned worldwide which lead to additional indirect costs. Using a suitable combination of renewable energies can be a key point to solve these issues [1]. Wind power systems have been harvesting energy from the wind for centuries, from the old Asbad windmills for grain grinding, dates back to $227 \mathrm{BC}$ in Iran, to the huge utility-scale wind farms for electricity generation that we have today [2]-[4]. Nowadays, wind power is the most rapidly growing and most widely utilized renewable energy technology. World wind energy capacity reached 318,529 MW by end of 2013, after 282,275 MW in 2012 , which is about $4 \%$ of worldwide electricity generation. Some countries feature very high shares; in Denmark (34\%) and Spain $(21 \%)$, wind energy has become the largest source of electricity; also Portugal (more than 20\%), Ireland (more than $16 \%$ ) and Germany (9\%) have reached high portions (WWEA, 2014). Nevertheless, the current wind power technology, i.e., wind towers, has several limitations that need

Manuscript received August 18, 2015; revised February 18, 2016.

Ken Nagasaka is with Tokyo University of A \& T, Tokyo, Japan (e-mail: bahman@cc.tuat.ac.jp).

Amin Amini is with Purdue School of Eng. \& Tech., Indiana, USA (e-mail: amin.amini.elec@gmail.com).

Mohammad V. Momeni is with Shahid Beheshti Univ. Tehran, Iran. to be overcome to make wind power source a strong competitor against fossil sources. Particularly, current wind towers require massive investments on account of the fact that they require heavy foundations and huge blades. Furthermore, the average $\mathrm{kW} / \mathrm{km}^{2}$ obtained by the current wind farms is 200-300 times lower than the same rated thermal power plants which would cause to significant land occupation and environmental fingerprints. Also, wind towers can operate at a maximum height of about $198 \mathrm{~m}$, due to structural limits, and can therefore be feasible only in locations with significant wind speed. Recent studies (see, e.g., [5]-[7]) have shown that these obstacles can be conquered by the developing technology of airborne wind turbine [8].

Airborne wind energy (AWE) systems are flying wind turbines that combine a number of known, and several innovative, technologies into a unique method of collecting clean, renewable energy. Their design and flexibility allow them to be deployed in areas that are otherwise unsuitable for traditional wind turbines [9]. They also obviate the existing concern over the visibility and bird collisions as well as the use of land [10]. Shrouding the rotor into a divergent duct in Horizontal-Axis Wind Turbine (HAWT) is a way to improve wind turbine efficiency and operational flexibility. This concept is called Diffuser-Augmented Wind Turbine (DAWT) [11] and is depicted in Fig. 1. The idea is to make a low-pressure zone behind the rotor to pull the fluid out of the internal duct to increases mass flow and power extraction.

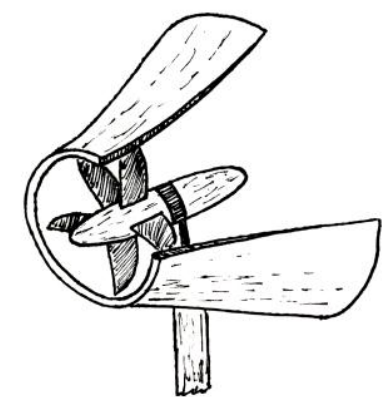

Fig. 1. A diffuser-augmented wind turbine (DAWT), sketch by author.

This paper explores the design, modeling and development of a new concept of DAWT. The basic idea is to capture high altitude wind power by having an embedded wind turbine in a dam-shaped membrane. The membrane is a kite, which makes positive pressure on windward side and negative pressure on the leeward side. Therefore, kite will lift the system and suck the air through the hole to create a practical floating wind turbine where the lift system and diffuser, shaped as a channeling device, takes an active role in the aerodynamic process of energy extraction instead of being just a passive component that only provides structural support for the turbine [12].

This novel airborne wind turbine, which will be referred to 
as "WindDam" in the following, is able to exploit wind flows at higher altitudes (up to $300 \mathrm{~m}$ ). At some elevations, wind is stronger and more persistent compare to the elevation when actual wind towers operate. Thus, this technology can be used in a much larger number of locations.

Moreover, this system lead to have higher power output compare to wind towers placed in the same location on account of the fact that the generated power grows with the cube of wind velocity [8]. Furthermore, the combination of nozzle and kite as a system also produces an acceleration of the incoming flow due to low-pressure region behind the kite, so it is another increment in the angular speed. Finally, a WinDam represents a much smaller landscape disturbance than a standard horizontal axis wind turbine (HAWT); therefore, would eliminate the concern over the visibility and noise of actual wind turbines as well as use of land. In contrast to older design of airborne wind turbines, where helium-inflated shell is a substantial element in the system, WinDam does not require any kind of gases or hot-air for operation. Due to all these reasons, it is expected that a WindDam will have a generated power density per kilometers squared much higher than actual wind turbines, very easy to build, and much lower energy production costs, even lower than fossil energy. A great number of small-scale WinDam prototypes were build and the good matching between Experimental data compared to computational fluid dynamics (CFD) analysis results shows that WinDam accelerates the free stream wind speed up to $137 \%$ at the location of turbine.

\section{NEW CONCEPT}

\section{A. WinDam Concept}

WinDam is a novel DAWT. The system composed of a tethered airfoil supporting an independent wind power generator payload. The design has been scaled to handle $5 \mathrm{~W}$ payload. Contrary to other systems the power generation and lift system in this design rely on each other for operation. Kite plays a very important role in the aerodynamic process of energy extraction instead of being just a passive component to fly the turbine. The lift system is a lighter-than air flyer with longitudinal and lateral control capabilities, and the tether serves to both anchor the device and to transmit electricity to the ground. Therefore, as is shown in Fig. 2, the two key parts of the WinDam system are (1) nozzle to accelerate and collect the wind, and (2) a kite for flying the system and having dam effect.

\section{B. Energy Conversion System}

For the nozzle, we can have (1), (2), (3), (4), for conservation of mass, axial and angular momentum balances, and energy conservation for inviscid, incompressible axisymmetric flows yields [13]:

$$
\begin{gathered}
\oint_{A} \rho V \cdot d A=0 \\
\oint_{A} v_{x} \rho V \cdot d A=F-\oint_{A} p d A \cdot n_{x}
\end{gathered}
$$

$$
\begin{gathered}
T=\oint_{A} r v_{\theta} \rho V \cdot d A \\
P_{\text {out }}=\oint_{A}\left[(p / \rho)+1 / 2\left\|V^{2}\right\|\right] \rho V \cdot d A
\end{gathered}
$$

where $V$ is the velocity vector; $r$ is the radius; $\rho$ is the density of air; $A$ is the outward-pointing area vector of the surface; $n_{x}$ is the unit vector in the $x$ direction. $p$ is the pressure; $F$ is the axial force acting on the rotor; $T$ is the torque; and $P_{\text {out }}$ is the power output of the turbine. The equation (4) represents the extracted wind power $P_{\text {out }}$ which can be increased by increasing the mass flow rate or the total energy drop across the turbine.

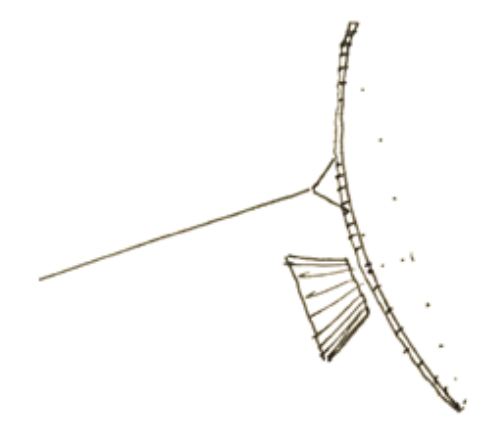

Fig. 2. First sketch of WinDam by the author.

The principles of the WinDam system are that the nozzle collects and accelerates wind and the kite creates a low pressure region behind the turbine and hence the mass flow rate is growing. Consequently, the WinDam system can more effectively converts the kinetic and potential energy of the wind to higher kinetic energy $1 / 2\left\|\mathrm{~V}^{2}\right\|$ and then it can more effectively be converted to mechanical rotation of a turbine.

\section{CFD (COMPUTATIONAL FLUID DyNAMIC) MODEL AND ANALYSIS}

The working concept of the WinDam is verified by simulations in computational fluid dynamics (CFD). Computational fluid dynamics was used for understanding and quantitative prediction of velocity and pressure fluctuations in two different scenarios for the WinDam. The only difference between two scenarios is having a nozzle which is the guide directing wind into the intake of the turbine. In scenario II, the nozzle contributes to further enhance intake's performance in capturing free stream flow rate. The geometric shapes were modeled in both scenarios are depicted in Fig. 3(a) and Fig. 3(b).

The WinDam was modeled using the commercial available package ANSYS. Moreover, the 8GB computer RAM was used for these simulations. The flow domain was discretized with a mesh of quadrilateral elements. High mesh resolution was used near the location of turbine in the ANSYS computations, as is depicted in Fig. 4. In both scenarios, the three-dimensional Reynolds-Averaged Navier-Stokes (RAN-S) equation were solved numerically with a second-order accuracy and standard k-epsilon turbulence model. The numerically calculated pressure and velocity changes are obtained by turbulence flow up to $\operatorname{Re}=10^{\wedge} 5$. The 
turbulence intensity was set at $5 \%$ in calculation as well.

A constant input velocity field, representing the free stream wind, was assigned to the entire frontal plane of the flow domain. The magnitude of the velocity was set at $19 \mathrm{~m} / \mathrm{s}(42.5$ $\mathrm{mph}$ ). The reference pressure was assumed to be the atmospheric pressure throughout the domain. (a)

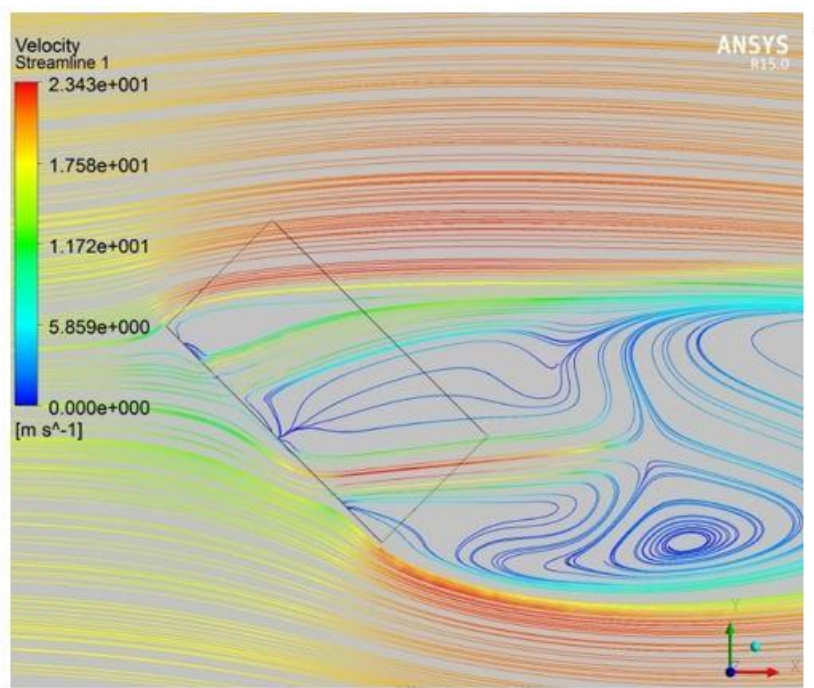

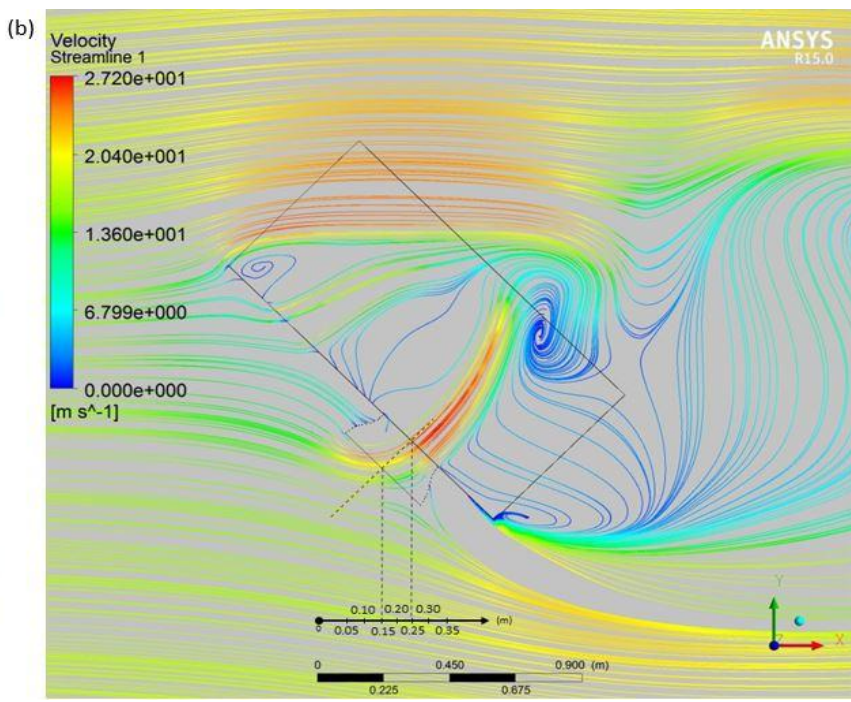

Fig. 3. Velocity magnitude distribution in ANSYS on the place of symmetry: (a) Scenario I; (b) Scenario II.

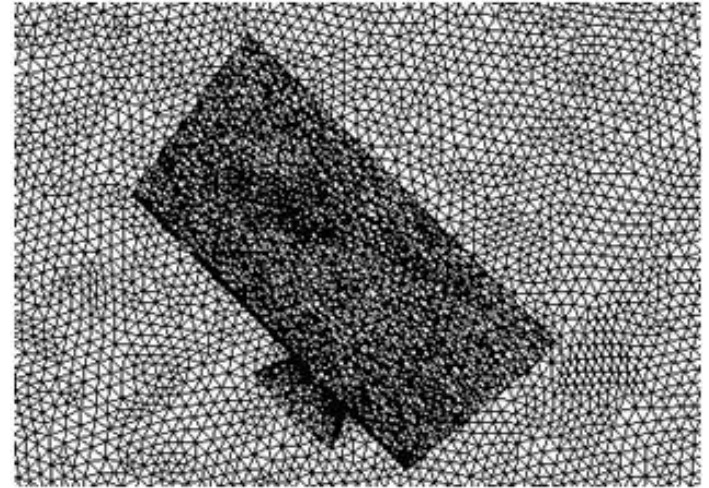

Fig. 4. Mesh elements in the simulation.

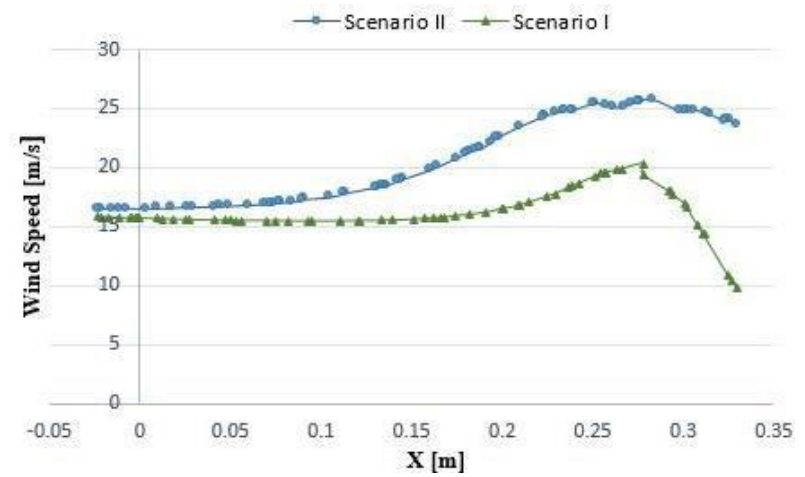

Fig. 5. Velocity-distance graphs for both scenarios.

From Fig. 3(b) it can be seen that the angle between free stream direction and axis of turbine is about $45^{\circ}$ angle. Thus, effective velocity, velocity vector parallel to the axis of the turbine, is calculated in (5).

$$
V_{\text {eff }}=V \times \cos (\theta)
$$

As can be seen in Fig. 3(b), the presence of nozzle would have some advantages; i.e., the flow at the location of the turbine appears to be more uniform. Moreover, the angle between the flow direction and the axis of turbine reaches zero. Therefore, the effective velocity and airflow velocity are the same. Detailed analysis on a straight imaginary line along the axis of turbine shows flow velocity fluctuations. Velocity-distance graphs are shown in Fig. 5 along the imaginary line for both scenarios.

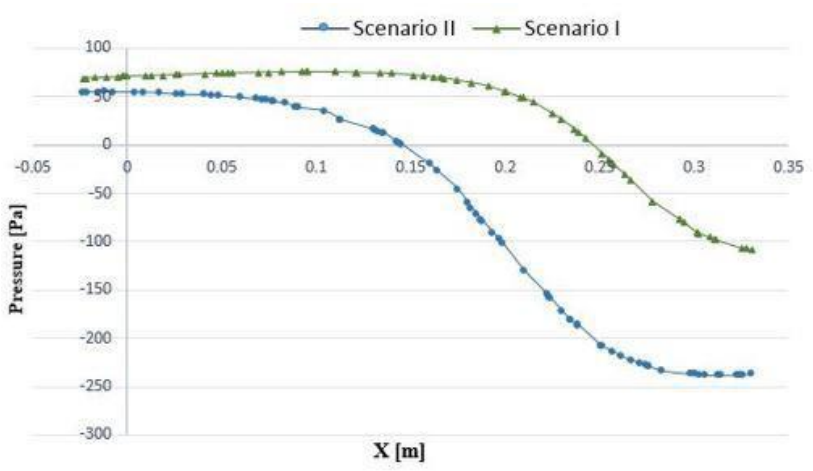

Fig. 6. Pressure-distance graphs for both scenarios.

It is noted that the nozzle is located from $0.15 \mathrm{~m}$ to $0.25 \mathrm{~m}$ and the turbine is embedded at $0.25 \mathrm{~m}$. As is clear from the graph, the derivative of velocity and velocity magnitude are higher in the presence of nozzle for all $x$. Regarding the constant free stream wind speed of $19 \mathrm{~m} / \mathrm{s}$, the effective velocity, $V_{\text {eff }}$, in the presence of nozzle reaches $26 \mathrm{~m} / \mathrm{s}$, whereas, based on (5), the maximum effective speed for the first scenario is $13.5 \mathrm{~m} / \mathrm{s}$. The effective wind speeds and the acceleration factor, which is the ratio of effective wind speed in the second scenario over the effective wind speed in the first scenario, as defined in (6), for 7 data sets are shown in Table I.

$$
A . F .=V_{\text {eff,II }} / V_{\text {eff,I }} \times 100
$$

Furthermore, the data reveals that in the second scenario the free stream wind speed accelerates up to $137 \%$ at the 
location of turbine. If the free stream wind speed is $19 \mathrm{~m} / \mathrm{s}$, the speed at the location of turbine will be equal to $26 \mathrm{~m} / \mathrm{s}$.

The paramount conclusion is that in Scenario II the nozzle can increase the effective velocity $193 \%$ higher than the Scenario I at the location of wind turbine. According to (7), the wind turbine power output, a small rise in velocity can have a major impact on power generation. Another important quantity which plays an essential role in this system is pressure. Fig. 6 shows the pressure-distance graphs which are also obtained along the imaginary line in both scenarios. As the line graph shows, the pressure behind the kite in both scenarios is greatly dropped. In fact, the kite acts as a dam against the wind creating a low pressure region behind the turbine. It should be noted that the nozzle would cause more pressure drop behind the kite in scenario II compare to scenario I.

$$
P_{\text {out }}=\frac{1}{2} \rho \cdot A \cdot V^{3}
$$

TABLE I: EFFECTIVE WIND SPEEDS FOR BOTH SCENARIO

\begin{tabular}{cccc}
\hline$X[\mathrm{~m}]$ & $V_{\text {eff, I }}[\mathrm{m} / \mathrm{s}]$ & $V_{\text {eff, II }}[\mathrm{m} / \mathrm{s}]$ & $A . F$. \\
\hline 0.00 & 11.09 & 16.55 & 149 \\
0.05 & 10.95 & 16.80 & 153 \\
0.10 & 10.92 & 17.30 & 158 \\
0.15 & 10.99 & 19.45 & 177 \\
0.20 & 11.66 & 22.62 & 194 \\
0.25 & 13.50 & 26.00 & 193 \\
0.30 & 11.73 & 24.82 & 212 \\
\hline
\end{tabular}

Consequently, low-pressure region draws more mass flow through the wind turbine which contributes increase in velocity. Therefore, kite plays an active role in the aerodynamic process of energy extraction instead of being just a passive component which lifts the turbine up to higher altitude.

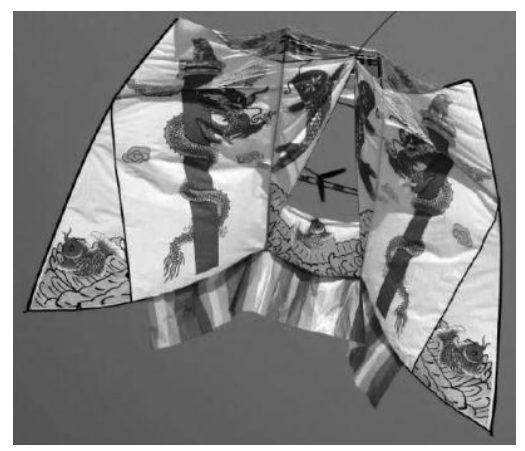

Fig. 7. WinDam prototype.

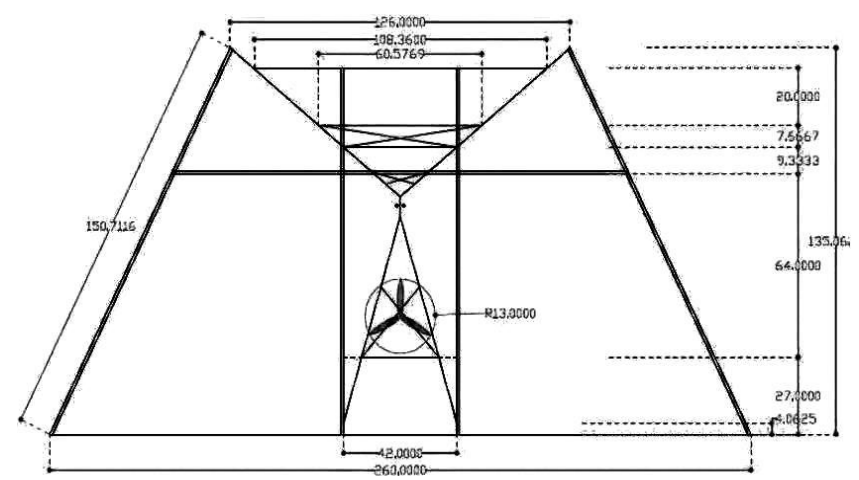

Fig. 8. Detailed dimensions and geometry of WinDam.

\section{EXPERIMENTAL RESULTS}

Wind speed at the location of turbine is calculated by carrying out a great number of flying experiments at different altitudes. One of the prototypes is illustrated in Fig. 7. Fig. 8 shows the detailed dimensions and geometry of WinDam in $\mathrm{cm}$. As is shown in Fig. 9, an embedded system is employed for acquiring wireless volt meter data to the ground then the wind speed were achieved by using the power curve of the generator, as the reference, for different wind speeds. The embedded system, FRDM-K64F, and the wireless module, ESP8266, have been used for sending and receiving the data through $\mathrm{WiFi}$, 802.11. It is worth pointing out that this method is the first of its kind to measure the wind speed at high altitudes by using power curve of the generator and has not been used in any related articles. In fact, this technique will allow you to have a real-time data logger for monitoring the wind speed without using anemometer. Table II shows the experimental results for two scenarios at different altitudes, $\mathrm{H}$. $V_{\mathrm{fs}}$ is the free stream wind speed; $V_{\text {eff, I }}$ is the wind speed at the location of turbine in the first scenario; $V_{\text {eff, II }}$ is the wind speed at the location of turbine in the second scenario, and A.F. is the acceleration factor which is defined in (6).
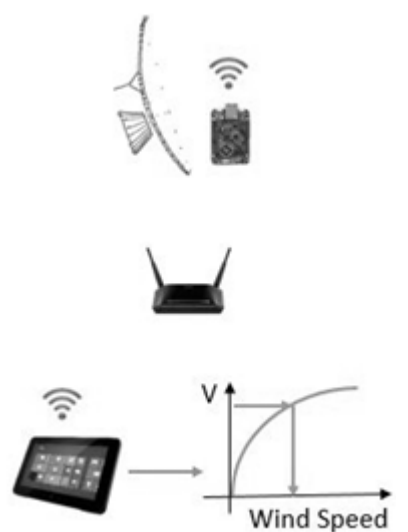

Fig. 9. System architecture.

TABLE II: EXPERIMENTAL RESULTS FOR TwO SCENARIOS AT DIFFERENT Altitudes

\begin{tabular}{ccccc}
\multicolumn{5}{c}{ ALTITUDES } \\
\hline$H[\mathrm{~m}]$ & $V_{\mathrm{fs}}[\mathrm{m} / \mathrm{s}]$ & $V_{\text {eff, I }}[\mathrm{m} / \mathrm{s}]$ & $V_{\text {eff, II }}[\mathrm{m} / \mathrm{s}]$ & $A . F$. \\
\hline 50 & 13.4 & 9.2 & 17.5 & 190 \\
80 & 16.8 & 11.6 & 21.9 & 189 \\
110 & 19 & 13.9 & 25.6 & 184 \\
140 & 22.5 & 16.4 & 29.8 & 182 \\
170 & 24.7 & 18.4 & 32.6 & 178 \\
200 & 26.8 & 19.2 & 34.2 & 178 \\
\hline
\end{tabular}

\section{CONCLUSION}

In this paper, design, modeling and development of a novel wind turbine, called WinDam, have been introduced. The good matching between experimental data compared to CFD analysis results show that it has the potential to overcome the limits of the actual wind turbines and to provide large quantities of renewable energy. The air flyer plays an important role in the system; it does not only lift the system up, but also decreases the pressure on the back of the turbine.

In contrast to other airborne wind turbines, WinDam does not require any kind of gases or hot-air for operation which makes this system cheaper and easy to use. However, one of 
the practical limitations in this project has been the control system. Proposing and applying an appropriate control system is necessary to be addressed in future works in order to control the direction and angle of the kite.

\section{REFERENCES}

[1] F. Lorenzo, M. Milanese, and D. Piga, "High-altitude wind power generation," IEEE Transactions on Energy Conversion, vol. 25, no. 1, pp. 168-180, 2010.

[2] L. Chen, F. L. Ponta, and L. I. Lago, "Perspectives on innovative concepts in wind-power generation," Energy for Sustainable Development, vol. 15, no. 4, pp. 398-410, 2011.

[3] A. Saeidian, M. R. Bemanian, E. Zamani, M. R. Pourjafar, and M. Gholi, "A survey in sustainable design of Iranian windmill technology in desert areas," Elixir Int. J., p. 48, 2012.

[4] A. Amini and M. Kamoona, "Hidden wind farms potential for residential households having roof-mounted wind arrester," in Proc. International Conference on Renewable Energy Research and Application (ICRERA), 2014, pp. 891-896.

[5] M. Canale, L. Fagiano, M. Milanese, and M. Ippolito, "Control of tethered airfoils for a new class of wind energy generator," in Proc. 45th Conf. Dec. Control, 2006, pp. 4020-4026.

[6] A. Ilzhöfer, B. Houska, and M. Diehl, "Nonlinear MPC of kites under varying wind conditions for a new class of large-scale wind power generators," Int. J. Robust Nonlinear Control, vol. 17, pp. 1590-1599, 2007.

[7] P. Williams, B. Lansdorp, and W. Ockels, "Optimal crosswind towing and power generation with tethered kites," J. Guid., Control, Dyn., vol. 31, pp. 81-93, 2008.

[8] M. Canale, L. Fagiano, and M. Milanese, "High altitude wind energy generation using controlled power kites," IEEE Transactions on Control Systems Technology, vol. 18, no. 2, pp. 279-293, 2010.

[9] N. White, N. Tierno, and M. Garcia-Sanz, "A novel approach to airborne wind energy: Design and modeling," Energy Tech., pp. 1-6, 2011.

[10] R. W. Bryan, D. H. Shepard, K. Caldeira, M. E. Cannon, D. G. Eccles, A. J. Grenier, and J. F. Freidin, "Harnessing high-altitude wind power,' IEEE Transactions on Energy Conversion, vol. 22, no. 1, pp. 136-144, 2007.

[11] L. Chen, F. L. Ponta, and L. I. Lago, "Perspectives on innovative concepts in wind-power generation," Energy for Sustainable Development, vol. 15, no. 4, pp. 398-410, 2011.

[12] P. Bizet, I. Amini, A. Houbakht, A. Amini, D. Zarnegar, and S. Sedghi, Regenerative Infrastructures: Freshkills Park NYC, Land Art Generator Initiative, Prestel Publication, April 2013, pp. 192-193.

[13] D. Allaei and Y. Andreopoulos, "INVELOX: Description of a new concept in wind power and its performance evaluation," Energy, vol. 69 , pp. $336-344,2014$.

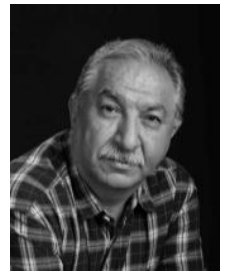

Ken Nagasaka received his $\mathrm{PhD}$ in electrical engineering from Tokyo Metropolitan University, 1990. He was a chief researcher at CSD Company, Tokyo, from 1990 to 1991. He had been a visiting professor at University of Manitoba, Winnipeg, Canada, from 1991 to 1994

$\mathrm{He}$ worked as a scientist at Central Research Institute of Electric Power Industry, Tokyo, from 1994 to 1998). He became an associate professor at the Department of Electrical Engineering of Tokyo Metropolitan University from 1995 to 1998. Since 1998, he taught and researched at the Graduate School of Engineering, Department of Electrical and Electronics Engineering of Tokyo University of Agriculture and Technology. Currently, he is a professor of Tokyo University of Agriculture and Technology. He has published more than 600 papers in the area of power systems, renewable energies and intelligent systems.

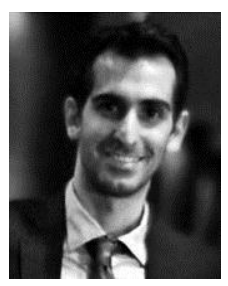

Amin Amini received his bachelor's degree in electrical engineering-transmission and distribution networks from Power and Water University of Technology, Tehran, Iran, 2013. Now he is doing his master's degree in electrical engineering at Purdue School of Engineering and Technology, IUPUI, Indiana, US.

Currently he is working as an energy auditor for Industrial Assessment Center, sponsored by US Department of Energy, Indianapolis, IN, US. He introduced "Hidden Wind Farm" concept in "Hidden wind farm potential for residential households having roof-mounted wind arrester" (ICRERA 2014, Milwaukee, US). His research interests include renewable energies, energy efficiency, and power systems.

Mr. Amini is a member of IEEE, ASHRAE and USGBC.

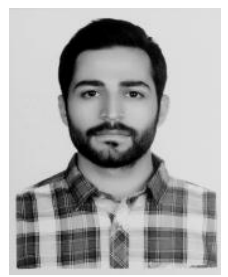

Mohammad Mehdi Vaez Momeni received the bachelor's degree in mechanical engineering from Shahid Beheshti University (SBU), Tehran, Iran, in 2014. From 2011 to 2013, he was a teacher assistant (TA) in the Department of Science, Shahid Beheshti University (SBU).

He was in charge of research assistant for Scientific Society of Mechanical Engineering Students at Shahid Beheshti University (from 2014 to 2015). His research interests include computational fluid dynamics (CFD), renewable energy, energy conversion systems, and tidal and wave energy. 
Clean Energy Technology 
